\title{
What is MRSA?
}

\author{
A. Pantosti* and M. Venditti ${ }^{\#}$
}

ABSTRACT: For decades methicillin-resistant Staphylococcus aureus (MRSA) has been considered the prototype of multi-resistant nosocomial pathogens, causing infections in highrisk patients. Changes in the healthcare system, coupled with the evolution of this versatile microorganism, have transformed MRSA into a cause of community-onset infections, in both patients who have contact with the healthcare system and patients without such a risk factor.

New lineages of MRSA, defined as community acquired (CA)-MRSA, have emerged that have a propensity to cause infections in young individuals without risk factors. CA-MRSA primarily causes skin infections and, rarely, necrotising pneumonia. In the USA, these strains belong to a single widespread clone, designated USA300, while in Europe they belong to a variety of clones. Most strains carry genes for the Panton-Valentine leukocidin, whose role in diseases is under debate.

In subjects living in the community who have contact with the healthcare system, MRSA strains of the nosocomial type are a frequent cause of infection and of pneumonia in particular. The detection of a large MRSA reservoir in pigs and the finding that professionally exposed individuals are colonised, has further shown that it is necessary to closely follow the epidemiology of MRSA if we want to combat it effectively.

KEYWORDS: Antibiotic resistance, community-acquired pneumonia, methicillin-resistant Staphylococcus aureus, necrotising pneumonia, nosocomial pneumonia, Staphylococcus aureus

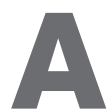
decade ago the question would have sounded quite trivial to microbiologists and infectious diseases specialists. The unanimous answer would have been that methicillin-resistant Staphylococcus aureus, or MRSA, is the prototype of multi-resistant bacterial pathogens and represents a major cause of nosocomial infections worldwide. Although this statement still holds true, today it represents only part of the story. During the past decade, the epidemiology of MRSA has changed greatly, requiring a change of perspective in our view of MRSA infections. The emergence and spread of MRSA in the community has changed the approach to empirical therapy for serious community-onset infections. Today, any serious infection that is potentially caused by staphylococci should be presumed to be due to MRSA until culture results are available.

This article will try to follow the rise and spread of the MRSA threat and the latest development of its extraordinary evolution. Only if you know your enemy, you are in a position to combat it more effectively.

\section{THE PATHOGENIC POTENTIAL OF $S$. AUREUS}

S. aureus is a ubiquitous microorganism that is able to colonise the anterior nares and other skin districts of healthy individuals. It has been estimated that $\sim 50 \%$ of adults are either persistent or intermittent $S$. aureus carriers [1]. This microorganism can become a versatile pathogen causing a broad spectrum of infections thanks to a large arsenal of virulence factors. S. aureus infections range from common skin infections, such as furunculosis and impetigo, to severe deep-seated infections. S. aureus ranks first or second among bacterial pathogens causing bloodstream infections according to different studies $[2,3]$, and is the leading cause of nosocomial pneumonia [4]. In addition, S. aureus causes infections of surgical wounds and prosthetic implants.

For editorial comments see page 1013.

Earn CME accreditation by answering questions about this article. You will find these at the back of the printed copy of this issue or online at www.erj.ersjournals.com $/ \mathrm{misc} / \mathrm{cmeinfo} . \mathrm{dtl}$

AFFILIATIONS

*Dept of Infectious, Parasitic and Immune-mediated Diseases, Istituto Superiore di Sanità, and \#Dept of Infectious Diseases, Policlinico Umberto I, University of Rome "Sapienza", Rome, Italy.

CORRESPONDENCE

A. Pantosti

Dept of Infectious, Parasitic and Immune-mediated Diseases Istituto Superiore di Sanità Viale Regina Elena 299

Rome 00161 Italy E-mail: annalisa.pantosti@iss.it

Received:

Jan 162009

Accepted after revision: June 052009 


\section{A BRIEF HISTORY OF MRSA}

When penicillin was discovered, $S$. aureus was exquisitely susceptible to it and $S$. aureus infections were effectively cured with the "wonder drug". However, in the course of a few years, $S$. aureus became capable of destroying penicillin by the production of a specific enzyme called penicillinase, encoded by a plasmid that spread quickly among different $S$. aureus strains [5]. Methicillin, a modified penicillin expressly designed to resist the destructive action of the staphylococcal penicillinase, became available for therapeutic use in 1959 but its success was short lived. After only 2 yrs, the first case of MRSA was reported [6]. This time resistance was not due to a hydrolysing enzyme, but to a more sophisticated mechanism. Methicillin, like all penicillins, exerts its action by blocking the proteins called penicillin binding protein (PBPs), which are responsible for the construction and maintenance of the bacterial cell wall. S. aureus resistant strains acquired a new protein, called $\mathrm{PBP} 2 \mathrm{a}$, which was not blocked by methicillin and could replace the other PBPs, thus allowing the survival of S. aureus in the presence of methicillin. PBP2a is encoded by the gene mecA, which is the hallmark of MRSA. As opposed to the penicillinase gene, mecA does not reside on a plasmid but on the chromosome, embedded in a large mobile genetic element called Staphylococcal Chromosome Cassette mec or SCCmec [7]. The presence of PBP2a means MRSA is not only resistant to methicillin but also to all $\beta$-lactam antibiotics, including synthetic penicillins, cephalosporins and carbapenems.

The march of MRSA had just started. After causing sporadic outbreaks of nosocomial infections for a several decades, at the turn of the 1980s MRSA started to become an endemic pathogen in hospitals in several countries [8].

\section{MRSA HIGHLIGHTS}

Methicillin resistance is considered such a distinctive characteristic of $S$. aureus that MRSA strains are viewed almost as a "subspecies" of S. aureus. Today methicillin is not used any more and in susceptibility tests it is replaced by oxacillin, a more stable anti-staphylococcal penicillin. Nevertheless, the acronym MRSA is still in use and has achieved notoriety even among the mass media and the general population.

Several phenotypic and genotypic characteristics differentiate methicillin-susceptible $S$. aureus (MSSA) from MRSA. First of all, MRSA tend to be multi-drug resistant, that is resistant not only to $\beta$-lactam antibiotics but also to a range of different antibiotic classes, such as fluoroquinolones, tetracyclines, macrolides, lincosamides and aminoglycosides [9, 10]. In previous years, strains have emerged with an intermediate susceptibility or full resistance to vancomycin (VISA and VRSA, respectively), the antibiotic that for two decades has represented the cornerstone of therapy for MRSA [11]. VISA originally appeared in Japan and was subsequently reported in the USA and in Europe [12, 13]. Some strains are called hetero-VISA because they appear to be vancomycin susceptible on routine tests but contain a minority of bacterial cells with intermediate vancomycin susceptibility which can expand following vancomycin exposure [14]. Hetero-VISA are probably not uncommon among MRSA. As for VRSA, only eight isolates have been identified to date, all in the USA, and mostly from the state of Michigan [15]. In these cases, the precursor of VRSA was a "simple" MRSA causing chronic infection, such as skin ulcers, often in association with a vancomycin-resistant enterococcus (VRE). Following prolonged vancomycin therapy, the MRSA became a VRSA by the acquisition of the genes for vancomycin resistance (vanA and the accompanying genes), possibly from the co-infecting VRE through plasmid exchange [9].

Besides VISA and VRSA, a number of strains exist that have "decreased susceptibility" to vancomycin. These strains are still considered susceptible by the sensitivity tests but high concentration of vancomycin, close to the "intermediate" level, are required to inhibit them (minimal inhibitory concentration $=2 \mathrm{mg} \cdot \mathrm{mL}^{-1}$ ). Decreased susceptibility makes serious infections poorly amenable by vancomycin treatment [16]. This might be especially true for MRSA pneumonia, due to suboptimal penetration of vancomycin in the alveolar lining fluid [17]. Resistance to the newest antibiotics licensed to treat MRSA infections, linezolid and daptomycin has already emerged [18-21], although it is confined to a few cases. Therefore, the problem is two-fold: the therapeutic options to treat MRSA infections are limited and, in addition, MRSA also tends to acquire resistance to the newest antibiotics.

\section{GENOTYPIC CHARACTERISTICS OF MRSA}

Contemporary methods to type bacteria are based on genotypic characteristics of the strains, i.e. characteristics of the genome, or presence of certain genes or genetic elements. These methods are used to differentiate strains or lineages inside the MRSA population for epidemiological purposes, or to track an outbreak or the source of a strain [22]. The most commonly used technique involves a special gel electrophoresis (pulsed-field gel electrophoresis; PFGE), which separates chromosomal fragments that can be subsequently visualised as patterns of bands [23]. Currently, sequence based methods are favoured, since they allow comparability between laboratories and the creation of global databases. For MRSA, three methods can be applied. 1) Multilocus sequence typing (MLST) is the reference method. Seven house-keeping genes are sequenced and the combination of alleles identified is unambiguously associated to a number that corresponds to the sequence type (ST) [22]. 2) Staphylococcal protein A typing (spa typing) is used specifically for $S$. aureus and is based on the sequence of the repeat region of protein A [24]. 3) SCCmec typing, based on the different structural characteristics of the genetic element that carries mecA, applies exclusively to MRSA. To date, seven SCCmec types and several variants have been described, with types I to $\mathrm{V}$ being the most common [25].

Some of the techniques described are depicted in figure 1. A particular MRSA strain can be described using one or more of these techniques; for instance, the community-acquired clone circulating in the USA is defined as USA300 by PFGE profile, ST8 by MLST, t008 by spa typing and type IV by SCCmec typing.

The molecular methods have revealed that MRSA are less heterogeneous than MSSA strains and only belong to five principal pandemic clonal complexes [26]. This means that not all MSSA can accept the SCCmec element to become MRSA [27] and that the evolution of MRSA is based essentially on clonal expansion. 
a)

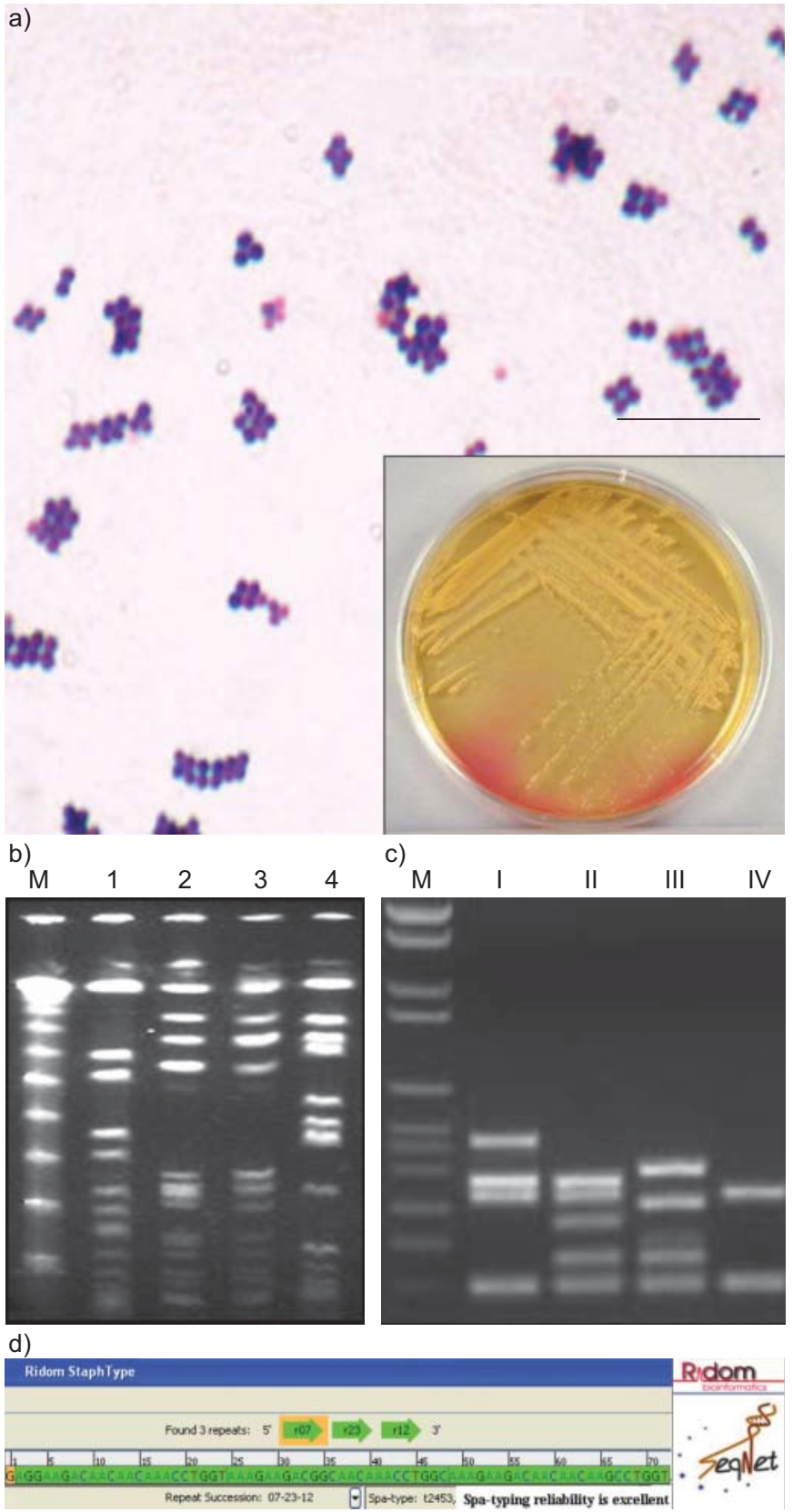

FIGURE 1. Methicillin-resistant Staphylococcus aureus (MRSA) from phenotype to genotype. a) Microscopic appearance of $S$. aureus. The inset shows growth of S. aureus on a selective plate (Mannitol salt agar). Scale bar $=10 \mu \mathrm{m}$. b) Pulsedfield gel electrophoresis to detect relatedness among different MRSA isolates. Isolates 2 and 3 appear very similar and are considered clonally related [22]. c) Multiple PCR for Staphylococcal Chromosome Cassette mec (SCCmec) typing, showing results for SCCmec type I, II, III and IV [25]. d) The Ridom Seq-Net website, in collaboration with Seq-Net (www.spaserver.ridom. de), for spa typing. The software analyses the DNA sequence of the protein A repeat region, recognises the different repeats (green arrows) and gives a spa type [24]. M: molecular size marker.

\section{EPIDEMIOLOGY OF MRSA IN HOSPITALS}

The proportion of MRSA infections in hospitals has increased steadily since the 1980s. The rise was documented at the beginning of the 1980s in Italy [28], later in that decade in the USA [8] and in the 1990s in the UK [29]. MRSA is now a worldwide problem and has become common not only in tertiary care and university hospitals, but also in smaller facilities. Data from the US National Nosocomial Infections Surveillance System found that in the $2003,60 \%$ of S. aureus in the Intensive Care Unit (ICU) were MRSA, an 11\% increase compared to the rate of the previous 5 yrs [30]. In this setting, MRSA is primarily a cause of bloodstream infections and of nosocomial pneumonia [31].

Data from the European Antibiotic Resistance Surveillance System showed a trend in the rise of MRSA until 2005, with the proportion of MRSA varying from $0 \%$ in the northern to $50 \%$ in southern European countries [32]. This striking difference is probably due to differences in antibiotic use and/or in the implementation of measures to control MRSA spread in hospitals [33]. In the last 2 yrs, several countries with a high proportion of MRSA, including the UK, Italy, France and Spain, reported a significant decrease, whereas an increase was observed in some low-level countries such as Finland, Denmark and the Netherlands. Nevertheless, the map of MRSA prevalence in Europe still shows a remarkable distinction between the rates of southern and western Europe and those of northern Europe (fig. 2).

A recent meta-analysis evaluating the impact of methicillin resistance on patient outcome in bacteremias has demonstrated that MRSA infections are associated with a significantly higher mortality rate than MSSA infections [34]. Patients with MRSA bacteremia are older, have more underlying diseases and are more likely to have severe sepsis than patients with MSSA infections [35]. However, among patients with pneumonia, there was no significant difference in mortality between patients with MRSA or MSSA [35]. Similarly, there was no difference in the outcomes of patients with ventilator-associated pneumonia (VAP) due to MRSA or MSSA after adjustment for severity at admission, time in ICU and adequacy of antibiotic treatment [36]

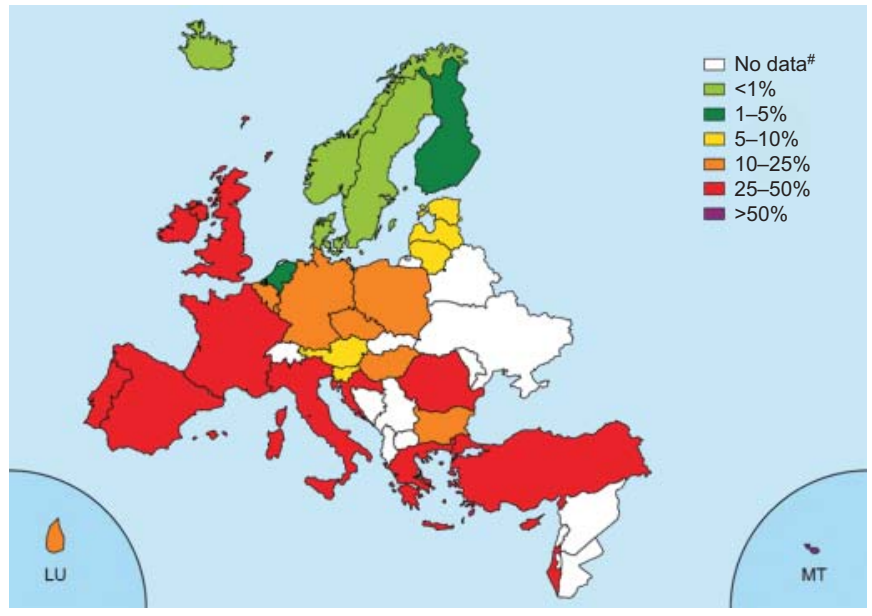

FIGURE 2. The proportion of methicillin-resistant Staphylococcus aureus (MRSA) isolates from bloodstream infections in Europe in 2007. ${ }^{*}$ : these countries did not report any data or reported $<10$ isolates. Reproduced from [32] with permission from the publisher. 


\section{COMMUNITY-ACQUIRED MRSA}

During the past decade, the epidemiology of MRSA infections has greatly changed with the emergence of a "new generation" of MRSA strains that have the propensity to cause infection in otherwise healthy subjects (children or young adults) living in the community. Community-acquired (CA)-MRSA have epidemiological, clinical and microbiological features that differentiate them from hospital-acquired (HA)-MRSA, although each characteristic is not exclusive of each group [37]. Typically, CA-MRSA strains cause skin and soft tissue infections $[38,39]$, including furuncles, abscesses, impetigo and cellulitis. Infections are often recurrent and outbreaks have been reported [17, 40,41]. Rarely, CA-MRSA are associated with severe infections with high mortality, such as sepsis and Waterhouse-Friderichsen syndrome [42, 43], necrotising fasciitis [44] and necrotising pneumonia [45]. Necrotising pneumonia occurs in young patients, is often preceded by influenza virus infection or an influenza-like illness, is characterised by multiple cavitating lung infiltrates and mortality can exceed $50 \%$ [46].

From a microbiological point of view, CA-MRSA differs from HA-MRSA due to a number of characteristics. CA-MRSA is usually susceptible to most non- $\beta$-lactam antibiotics [39] and contains an SCCmec element of type IV, type V or of the newly described type VII [47]. Conversely, HA-MRSA is typically multidrug-resistant and contains an SCCmec element of type I, II or III. In addition, most CA-MRSA isolates carry the phageencoded Panton-Valentine leukocidin (PVL) [48], a toxin with the ability to cause lysis of human leukocytes and necrosis of epithelial cells [49]. PVL has been primarily associated with skin infections and with necrotising pneumonia [50] and most contemporary CA-MRSA isolates causing severe infections produce PVL [51-53]. However, the role played by PVL in the pathogenesis of $S$. aureus infections is still controversial and animal models have produced conflicting results [54,55]. Since $S$. aureus is endowed with a large armamentarium of toxins [56], it is possible that PVL can act in synergy with the other toxins or in certain phases of the infection only [57].

CA-MRSA strains are globally spread, although their prevalence in the community varies widely from area to area. In the USA, a single CA-MRSA clone, designated USA300, has become prevalent [58]. USA300, the prototype of CA-MRSA, has recently started to enter the healthcare system, causing infections and outbreaks among neonates [59], nosocomial bloodstream infections [60] and colonisation in residents of long-term care facilities [61].

In Europe, the prevalence of infections due to CA-MRSA is lower than in the USA, although it appears to be on the increase. In a French hospital, the incidence of CA-MRSA skin and soft-tissue infections increased from $0 \%$ to $6.8 \%$ in a $3-y r$ period [62]. In Copenhagen, the number of MRSA isolates, mainly obtained from community-acquired skin infections, doubled in $<1$ yr from 2003 to 2004 [63]. CA-MRSA isolates from European countries belong to a variety of different clones and lineages and the majority carry the PVL genes [48]. The most common European CA-MRSA clone is ST80, otherwise defined the "European clone" [64]. Other frequently identified clones are ST30, originally defined as the West Pacific clone, and the USA300 clone $[52,65]$.
The typical CA-MRSA, originally susceptible to most non- $\beta$ lactam antibiotics is evolving towards multiple-antibiotic resistance. Multiple-drug resistant USA300 isolates that have acquired a plasmid which carries antibiotic resistance genes have been recently identified in the USA [66]. In Europe, the ST80 clone is characteristically resistant to fluoroquinolones, tetracyclines and fusidic acid [67], and the other circulating clone can prove resistant to different antibiotics, including aminoglycosides [68].

\section{MRSA IN HEALTHCARE-ASSOCIATED INFECTIONS AND HEALTHCARE-ASSOCIATED PNEUMONIA}

Traditionally, infections occurring in patients residing in the community or infections occurring within 48-72 h following hospital admission have been categorised as communityacquired. In previous years, changes in the healthcare system have modified the epidemiology of infections and this definition does not appear adequate for all cases. An increasing number of patients who have been recently discharged from hospitals and/or receive medical treatment (chronic haemodialysis, rehabilitation therapy and i.v. therapy) live in the community or reside in nursing homes or chronic care facilities. These patients can be colonised by typical HAMRSA [39] rather than CA-MRSA and the carriage state can persist for $>6$ months [69]. The definition of "healthcareassociated infections" (HCAI) has been proposed for infections occurring in patients living in the community and having contact with the healthcare system [70]. In European countries with high HA-MRSA rates, such as Italy or the UK, the majority of MRSA infections acquired in the community occur in patients with risk factors and are, in fact, HCAI [71-74].

Following this new definition, pneumonia occurring in the community or within $24-72 \mathrm{~h}$ following hospital admission can be a typical community acquired-pneumonia (CAP) or rather a healthcare associated pneumonia (HCAP) according to the characteristics of the patient. Clinically, HCAP is similar to hospital-acquired pneumonia (HAP) being associated to similar comorbidities, pneumonia severity scores and mortality rates [75-77]. Along the same line, the bacterial pathogens that cause HCAP are different from those causing CAP, more closely resembling those associated with HAP. HCAP pathogens are often multi-resistant and commonly include MRSA. A retrospective study performed in $>4,500$ patients from 59 USA hospitals between 2002 and 2004 identified MRSA as the most common pathogen in HCAP $(26 \%)$ while in CAP, MRSA was outnumbered by MSSA (8.9\% versus $17 \%$ ) and Streptococcus pneumoniae. The frequency of occurrence of MRSA in HAP and VAP were $22.9 \%$ and $14 \%$, respectively [76].

In a prospective study conducted in a single center in Barcelona (Spain), the role of MRSA appeared to be less prominent; however, $S$. aureus was isolated more frequently in HCAP than in CAP (2.4\% versus $0 \%$ ) [78]. In a multicentre prospective study from Italy conducted on 362 patients with pneumonia admitted to Internal Medicine wards [77], the bacterial pathogens were identified in $23 \%$ of the patients: $S$. aureus was isolated in $39 \%$ of culture-positive HCAP and in $50 \%$ of HAP, versus $17 \%$ of CAP. In HCAP and HAP the majority of $S$. aureus isolates were MRSA (personal communication; M. Venditti, Dept of Infectious Diseases, Policlinico Umberto I, University of Rome "Sapienza", Rome, Italy). 
Recognising HCAP and the role played by MRSA in this category of pneumonia is essential to provide an adequate empiric antibiotic therapy.

\section{MRSA INFECTION AS A ZOONOSIS}

MRSA can colonise animals and zoonotic strains of MRSA are emerging [79]. Companion animals such as cats and dogs can occasionally be colonised or infected with MRSA. Strains from companion animals are generally similar to HA-MRSA suggesting that they have been transmitted from the owners to their pets that, in turn, can act as reservoirs for infection or re-infection of humans [80]. In a previous study, MRSA has been isolated from horses and from the staff caring for them [79]. The most intriguing and worrying association is that of a particular lineage of MRSA with pigs. The pig lineage can be only identified on the basis of molecular markers: strains are nontypable by PFGE, belong to ST398 and to a range of associated spa types, such as t011, t108 and t899. In the Netherlands, over $30 \%$ of pigs at the slaughterhouse carry ST398 MRSA [81]. In this country with a very low rate of HAMRSA and a large pig population, pigs represent a major reservoir of MRSA. Colonisation of pigs with ST398 has been shown in several other European countries including France [79], Denmark [82], Germany, Austria [83] and in Canada, where a strain related to ST398 has been found [84]. The pigadapted MRSA strains are responsible for a number of cases of unexpected colonisation of individuals in contact with pigs, such as farmers [82], veterinarians [85] and their close relatives. In the Netherlands, $20 \%$ of the pig farmers carry MRSA. Occasionally, the pig strains can cause human infections [82]. Serious soft-tissue infections in professionally exposed individuals due to ST398 MRSA have been recently reported in Italy [86]. A small hospital outbreak occurred in Denmark in 2007 [87] indicating that the pig lineage is capable of inter-human spread. The impact and the implications of the emergence of this new virulent strain are still not fully understood.

\section{KNOW THINE ENEMY}

MRSA has an extraordinary adaptive power in terms of acquisition of both new virulence traits and antibioticresistance determinants. The changes that have occurred in the society of industrialised countries, from healthcare system organisation to the production of food animals, has opened new niches for this microorganism. MRSA still remains the most feared multiple-antibiotic resistant pathogen in the hospital setting, especially in ICUs, but it is also the most important cause of infections in dialysis centres. At present, MRSA is the most frequent cause of skin and soft infections in the community in the USA. In Europe, reports of MRSA outbreaks and serious infections in the community are increasing each year. MRSA has been found in pets and in food animals, including pigs and cows and subjects professionally exposed to pig farming are considered to be at risk for MRSA colonisation and infection.

These new aspects have important implications for the empiric treatment of patients in the community or in the emergency department. Clinicians increasingly face the dilemma of including therapy against MRSA for a possible or proven $S$. aureus infection acquired in the community, not only for patients with HCAI and risk factors for HA-MRSA, but also for patients without risk factors who may have a CA-MRSA infection. Treatment should always be selected on the basis of local epidemiology and antibiotic susceptibility patterns. The evolving epidemiology of MRSA requires close monitoring both at the national and local level in hospitals and the community. The attitude to perform a diagnostic procedure is lower in the community than in the hospital, but microbiological cultures should be performed whenever possible, bacterial strains should be identified and antibiotic susceptibility performed. In the case of a community-onset MRSA infection, the strain should be genotyped by a reference laboratory. Not only will this procedure bring benefit to the individual patient, but it will also contribute to promoting knowledge about the type of strains and clones circulating in the local community, in order to take control measures and define control strategies. Only a deep knowledge of the enemy will allow us to develop and use the right weapons to combat this battle.

\section{STATEMENT OF INTEREST}

A statement of interest for M. Venditti can be found at www.erj. ersjournals.com $/ \mathrm{misc} /$ statements.dtl

\section{REFERENCES}

1 Wertheim H, Melles D, Vos M, et al. The role of nasal carriage in Staphylococcus aureus infections. Lancet Infect Dis 2005; 5: 751-762.

2 Biedenbach D, Moet G, Jones R. Occurrence and antimicrobial resistance pattern comparisons among bloodstream infection isolates from the SENTRY Antimicrobial Surveillance Program (1997-2002). Diagn Microbiol Infect Dis 2004; 50: 59-69.

3 Wisplinghoff $\mathrm{H}$, Bischoff T, Tallent SM, et al. Nosocomial bloodstream infections in US hospitals: analysis of 24,179 cases from a prospective nationwide surveillance study. Clin Infect Dis 2004; 39: 309-317.

4 Hoban D, Biedenbach D, Mutnick A, et al. Pathogen of occurrence and susceptibility patterns associated with pneumonia in hospitalized patients in North America: results of the SENTRY Antimicrobial Surveillance Study (2000). Diagn Microbiol Infect Dis 2003; 45: 279-285.

5 Lyon B, Skurray R. Antimicrobial resistance of Staphylococcus aureus: genetic basis. Microbiol Rev 1987; 51: 88-134.

6 Jevons M. “Celbenin”--resistant staphylococci. Br Med J 1961; 1: 124.

7 Katayama Y, Ito T, Hiramatsu K. A new class of genetic element, staphylococcus cassette chromosome mec, encodes methicillin resistance in Staphylococcus aureus. Antimicrob Agents Chemother 2000; 44: 1549-1555.

8 Panlilio A, Culver D, Gaynes R, et al. Methicillin-resistant Staphylococcus aureus in U.S. hospitals, 1975-1991. Infect Control Hosp Epidemiol 1992; 13: 582-586.

9 Pantosti A, Sanchini A, Monaco M. Mechanisms of antibiotic resistance in Staphylococcus aureus. Future Microbiol 2007; 2: 323-334.

10 Hope R, Livermore DM, Brick G, et al. Non-susceptibility trends among staphylococci from bacteraemias in the UK and Ireland, 2001-06. J Antimicrob Chemother 2008; 62: Suppl. 2, ii65-ii74.

11 Chambers $\mathrm{H}$. Treatment of infections and colonization caused by methicillin-resistant Staphylococcus aureus. Infect Control Hosp Epidemiol 1991; 12: 29-35.

12 Hiramatsu $\mathrm{K}$, Hanaki $\mathrm{H}$, Ino $\mathrm{T}$, et al. Methicillin-resistant Staphylococcus aureus clinical strain with reduced vancomycin susceptibility. J Antimicrob Chemother 1997; 40: 135-136.

13 Tenover $\mathrm{F}$, Biddle $\mathrm{J}$, Lancaster $\mathrm{M}$. Increasing resistance to vancomycin and other glycopeptides in Staphylococcus aureus. Emerg Infect Dis 2001; 7: 327-332. 
14 Liu C, Chambers H. Staphylococcus aureus with heterogeneous resistance to vancomycin: epidemiology, clinical significance, and critical assessment of diagnostic methods. Antimicrob Agents Chemother 2003; 47: 3040-3045.

15 Sievert DM, Rudrik JT, Patel JB, et al. Vancomycin-resistant Staphylococcus aureus in the United States, 2002-2006. Clin Infect Dis 2008; 46: 668-674.

16 Tenover FC, Moellering RC Jr. The rationale for revising the Clinical and Laboratory Standards Institute vancomycin minimal inhibitory concentration interpretive criteria for Staphylococcus aureus. Clin Infect Dis 2007; 44: 1208-1215.

17 Stevens D. The role of vancomycin in the treatment paradigm. Clin Infect Dis 2006; 42: Suppl. 1, S51-S57.

18 Jones RN, Ross JE, Castanheira M, et al. United States resistance surveillance results for linezolid (LEADER Program for 2007). Diagn Microbiol Infect Dis 2008; 62: 416-426.

19 Peeters MJ, Sarria JC. Clinical characteristics of linezolid-resistant Staphylococcus aureus infections. Am J Med Sci 2005; 330: 102-104.

20 Marty FM, Yeh WW, Wennersten CB, et al. Emergence of a clinical daptomycin-resistant Staphylococcus aureus isolate during treatment of methicillin-resistant Staphylococcus aureus bacteremia and osteomyelitis. J Clin Microbiol 2006; 44: 595-597.

21 Murthy MH, Olson ME, Wickert RW, et al. Daptomycin nonsusceptible meticillin-resistant Staphylococcus aureus USA 300 isolate. J Med Microbiol 2008; 57: 1036-1038.

22 Faria NA, Carrico JA, Oliveira DC, et al. Analysis of typing methods for epidemiological surveillance of both methicillinresistant and methicillin-susceptible Staphylococcus aureus strains. J Clin Microbiol 2008; 46: 136-144.

23 Chung M, de Lencastre $H$, Matthews $P$, et al. Molecular typing of methicillin-resistant Staphylococcus aureus by pulsed-field gel electrophoresis: comparison of results obtained in a multilaboratory effort using identical protocols and MRSA strains. Microb Drug Resist 2000; 6: 189-198.

24 Shopsin B, Gomez M, Montgomery SO, et al. Evaluation of protein A gene polymorphic region DNA sequencing for typing of Staphylococcus aureus strains. J Clin Microbiol 1999; 37: 3556-3563.

25 Milheirico C, Oliveira DC, de Lencastre H. Update to the multiplex PCR strategy for assignment of mec element types in Staphylococcus aureus. Antimicrob Agents Chemother 2007; 51: 3374-3377.

26 Enright MC, Robinson DA, Randle G, et al. The evolutionary history of methicillin-resistant Staphylococcus aureus (MRSA). Proc Natl Acad Sci USA 2002; 99: 7687-7692.

27 Oliveira D, Tomasz A, de Lencastre H. Secrets of success of a human pathogen: molecular evolution of pandemic clones of meticillin-resistant Staphylococcus aureus. Lancet Infect Dis 2002; 2: 180-189.

28 Varaldo P, Montanari M, Biavasco F, et al. Stafilococchi meticillinoresistenti: aspetti microbiologici e problemi connessi [Methicillinresistant staphylococci: microbiological aspects and related issues]. Giornale Italiano delle Infezioni Ospedaliere 1994; 1: 105-110.

29 Speller DC, Johnson AP, James D, et al. Resistance to methicillin and other antibiotics in isolates of Staphylococcus aureus from blood and cerebrospinal fluid, England and Wales, 1989-95. Lancet 1997; 350: $323-325$.

30 National Nosocomial Infections Surveillance System, National Nosocomial Infections Surveillance (NNIS) System Report, data summary from January 1992 through June 2004, issued October 2004. Am J Infect Control 2004; 32: 470-485.

31 Rubinstein E, Kollef MH, Nathwani D. Pneumonia caused by methicillin-resistant Staphylococcus aureus. Clin Infect Dis 2008; 46 : Suppl. 5, S378-S385.

32 European Antimicrobial Resistance Surveillance System. EARSS Annual Report 2007. Available from: www.rivm.nl/earss/ Images/EARSS\%202007_FINAL_tcm61-55933.pdf
33 Tiemersma EW, Bronzwaer SL, Lyytikainen O, et al. Methicillinresistant Staphylococcus aureus in Europe, 1999-2002. Emerg Infect Dis 2004; 10: 1627-1634.

34 Cosgrove SE, Sakoulas G, Perencevich EN, et al. Comparison of mortality associated with methicillin-resistant and methicillinsusceptible Staphylococcus aureus bacteremia: a meta-analysis. Clin Infect Dis 2003; 36: 53-59.

35 Shurland S, Zhan M, Bradham DD, et al. Comparison of mortality risk associated with bacteremia due to methicillin-resistant and methicillin-susceptible Staphylococcus aureus. Infect Control Hosp Epidemiol 2007; 28: 273-279.

36 Zahar JR, Clec'h C, Tafflet $\mathrm{M}$, et al. Is methicillin resistance associated with a worse prognosis in Staphylococcus aureus ventilator-associated pneumonia? Clin Infect Dis 2005; 41: 1224-1231.

37 David MZ, Glikman D, Crawford SE, et al. What is communityassociated methicillin-resistant Staphylococcus aureus? J Infect Dis 2008; 197: 1235-1243.

38 King MD, Humphrey BJ, Wang YF, et al. Emergence of community-acquired methicillin-resistant Staphylococcus aureus USA 300 clone as the predominant cause of skin and soft-tissue infections. Ann Intern Med 2006; 144: 309-317.

39 Naimi TS, LeDell KH, Como-Sabetti $\mathrm{K}$, et al. Comparison of community- and health care-associated methicillin-resistant Staphylococcus aureus infection. JAMA 2003; 290: 2976-2984.

40 Main CL, Jayaratne P, Haley A, et al. Outbreaks of infection caused by community-acquired methicillin-resistant Staphylococcus aureus in a Canadian correctional facility. Can J Infect Dis Med Microbiol 2005; 16: 343-348.

41 Urth T, Juul G, Skov R, et al. Spread of a methicillin-resistant Staphylococcus aureus ST80-IV clone in a Danish community. Infect Control Hosp Epidemiol 2005; 26: 144-149.

42 Gonzalez BE, Martinez-Aguilar G, Hulten KG, et al. Severe staphylococcal sepsis in adolescents in the era of communityacquired methicillin-resistant Staphylococcus aureus. Pediatrics 2005 115: 642-648.

43 Adem PV, Montgomery CP, Husain AN, et al. Staphylococcus aureus sepsis and the Waterhouse-Friderichsen syndrome in children. N Engl J Med 2005; 353: 1245-1251.

44 Miller LG, Perdreau-Remington F, Rieg G, et al. Necrotizing fasciitis caused by community-associated methicillin-resistant Staphylococcus aureus in Los Angeles. N Engl J Med 2005; 352: 1445-1453.

45 Francis JS, Doherty MC, Lopatin U, et al. Severe community-onset pneumonia in healthy adults caused by methicillin-resistant Staphylococcus aureus carrying the Panton-Valentine leukocidin genes. Clin Infect Dis 2005; 40: 100-107.

46 Centers for Disease Control and Prevention (CDC).: Severe methicillin-resistant Staphylococcus aureus community-acquired pneumonia associated with influenza - Louisiana and Georgia, December 2006-January 2007. Morb Mortal Wkly Rep 2007; 56: 325-329.

47 Higuchi W, Takano T, Teng LJ, et al. Structure and specific detection of staphylococcal cassette chromosome mec type VII Biochem Biophys Res Commun 2008; 377: 752-756.

48 Tristan A, Bes M, Meugnier H, et al. Global distribution of PantonValentine leukocidin-positive methicillin-resistant Staphylococcus aureus, 2006. Emerg Infect Dis 2007; 13: 594-600.

49 Boyle-Vavra S, Daum RS. Community-acquired methicillin-resistant Staphylococcus aureus: the role of Panton-Valentine leukocidin. Lab Invest 2007; 87: 3-9.

50 Lina G, Piemont Y, Godail-Gamot F, et al. Involvement of PantonValentine leukocidin-producing Staphylococcus aureus in primary skin infections and pneumonia. Clin Infect Dis 1999; 29: 1128-1132.

51 Monaco M, Antonucci R, Palange P, et al. Methicillin-resistant Staphylococcus aureus necrotizing pneumonia. Emerg Infect Dis 2005; 11: 1647-1648

52 Valentini P, Parisi G, Monaco M, et al. An uncommon presentation for a severe invasive infection due to methicillin-resistant 
Staphylococcus aureus clone USA300 in Italy: a case report. Ann Clin Microbiol Antimicrob 2008; 7: 11.

53 Etienne J. Panton-Valentine leukocidine: a marker of severity for Staphylococcus aureus infections? Clin Infect Dis 2005; 41: 591-593.

54 Labandeira-Rey M, Couzon F, Boisset S, et al. Staphylococcus aureus Panton Valentine leukocidin causes necrotizing pneumonia. Science 2007; 315: 1130-1133.

55 Bubeck Wardenburg J, Bae T, Otto M, et al. Poring over pores: $\alpha$ hemolysin and Panton-Valentine leukocidin in Staphylococcus aureus pneumonia. Nat Med 2007; 13: 1405-1406.

56 Diep B, Carleton H, Chang R, et al. Roles of 34 virulence genes in the evolution of hospital- and community-associated strains of methicillin-resistant Staphylococcus aureus. J Infect Dis 2006; 193: 1495-1503.

57 Diep BA, Palazzolo-Ballance AM, Tattevin P, et al. Contribution of Panton-Valentine leukocidin in community-associated methicillin-resistant Staphylococcus aureus pathogenesis. PLoS ONE 2008; 3: e3198.

58 Moran GJ, Krishnadasan A, Gorwitz RJ, et al. Methicillin-resistant Staphylococcus aureus infections among patients in the emergency department. N Engl J Med 2006; 355: 666-674.

59 Nguyen D, Bancroft E, Mascola L, et al. Risk factors for neonatal methicillin-resistant Staphylococcus aureus infection in a well-infant nursery. Infect Cont Hosp Epidemiol 2007; 28: 406-411.

60 Seybold U, Kourbatova E, Johnson J, et al. Emergence of community-associated methicillin-resistant Staphylococcus aureus USA 300 genotype as a major cause of health care-associated bloodstream infections. Clin Infect Dis 2006; 42: 647-656.

61 Mody L, Kauffman CA, Donabedian S, et al. Epidemiology of Staphylococcus aureus colonization in nursing home residents. Clin Infect Dis 2008; 46: 1368-1373.

62 Del Giudice P, Blanc V, Durupt F, et al. Emergence of two populations of methicillin-resistant Staphylococcus aureus with distinct epidemiological, clinical and biological features, isolated from patients with community-acquired skin infections. $\mathrm{Br} J$ Dermatol 2006; 154: 118-124.

63 Bartels M, Boye K, Larsen A, et al. Rapid increase of geneticallydiverse methicillin-resistant Staphylococcus aureus, Copenhagen, Denmark. Emerg Infect Dis 2007; 13: 1533-1540.

64 Vandenesch F, Naimi T, Enright MC, et al. Community-acquired methicillin-resistant Staphylococcus aureus carrying PantonValentine leukocidin genes: worldwide emergence. Emerg Infect Dis 2003; 9: 978-984.

65 Witte W, Strommenger B, Cuny C, et al. Methicillin-resistant Staphylococcus aureus containing the Panton-Valentine leucocidin gene in Germany in 2005 and 2006. J Antimicrob Chemother 2007; 60: 1258-1263.

66 Diep BA, Chambers HF, Graber CJ, et al. Emergence of multidrugresistant, community-associated, methicillin-resistant Staphylococcus aureus clone USA 300 in men who have sex with men. Ann Intern Med 2008; 148: 249-257.

67 Witte W, Braulke C, Cuny C, et al. Emergence of methicillinresistant Staphylococcus aureus with Panton-Valentine leukocidin genes in central Europe. Eur J Clin Microbiol Infect Dis 2005; 24: 1-5.

68 Gerogianni I, Mpatavanis G, Gourgoulianis K, et al. Combination of staphylococcal chromosome cassette SCCmec type $\mathrm{V}$ and Panton-Valentine leukocidin genes in a methicillin-resistant Staphylococcus aureus that caused necrotizing pneumonia in Greece. Diagn Microbiol Infect Dis 2006; 56: 213-216.
69 Scanvic A, Denic L, Gaillon S, et al. Duration of colonization by methicillin-resistant Staphylococcus aureus after hospital discharge and risk factors for prolonged carriage. Clin Infect Dis 2001; 32: 1393-1398.

70 Friedman ND, Kaye KS, Stout JE, et al. Health care-associated bloodstream infections in adults: a reason to change the accepted definition of community-acquired infections. Ann Intern Med 2002; 137: 791-797.

71 Scudeller L, Leoncini O, Boni S, et al. MRSA carriage: the relationship between community and healthcare setting. A study in an Italian hospital. J Hosp Infect 2000; 46: 222-229.

72 Drapeau CM, Angeletti C, Festa A, et al. Role of previous hospitalization in clinically-significant MRSA infection among HIV-infected inpatients: results of a case-control study. BMC Infect Dis 2007; 7: 36.

73 Miller R, Esmail H, Peto T, et al. Is MRSA admission bacteraemia community-acquired? A case control study. J Infect 2008; 56: 163-170.

74 Rollason J, Bastin L, Hilton AC, et al. Epidemiology of communityacquired meticillin-resistant Staphylococcus aureus obtained from the UK West Midlands region. J Hosp Infect 2008; 70: 314-320.

75 Carratala J, Garcia-Vidal C. What is healthcare-associated pneumonia and how is it managed? Curr Opin Infect Dis 2008; 21: 168-173.

76 Kollef MH, Shorr A, Tabak YP, et al. Epidemiology and outcomes of health-care-associated pneumonia: results from a large US database of culture-positive pneumonia. Chest 2005; 128: 3854-3862.

77 Venditti M, Falcone M, Corrao S, et al. Outcomes of patients hospitalized with community-acquired, health care-associated, and hospital-acquired pneumonia. Ann Intern Med 2009; 150: 19-26.

78 Carratala J, Mykietiuk A, Fernandez-Sabe N, et al. Health careassociated pneumonia requiring hospital admission: epidemiology, antibiotic therapy, and clinical outcomes. Arch Intern Med 2007; 167: 1393-1399.

79 Morgan M. Methicillin-resistant Staphylococcus aureus and animals: zoonosis or humanosis? J Antimicrob Chemother 2008; 62: 1181-1187.

80 Strommenger B, Kehrenberg C, Kettlitz C, et al. Molecular characterization of methicillin-resistant Staphylococcus aureus strains from pet animals and their relationship to human isolates. J Antimicrob Chemother 2006; 57: 461-465.

81 de Neeling AJ, van den Broek MJ, Spalburg EC, et al. High prevalence of methicillin resistant Staphylococcus aureus in pigs. Vet Microbiol 2007; 122: 366-372.

82 Lewis HC, Molbak K, Reese C, et al. Pigs as source of methicillinresistant Staphylococcus aureus CC398 infections in humans, Denmark. Emerg Infect Dis 2008; 14: 1383-1389.

83 Witte W, Strommenger B, Stanek C, et al. Methicillin-resistant Staphylococcus aureus ST398 in humans and animals, Central Europe. Emerg Infect Dis 2007; 13: 255-258.

84 Khanna T, Friendship R, Dewey C, et al. Methicillin resistant Staphylococcus aureus colonization in pigs and pig farmers. Vet Microbiol 2008; 128: 298-303.

85 Wulf MW, Sorum M, van Nes A, et al. Prevalence of methicillinresistant Staphylococcus aureus among veterinarians: an international study. Clin Microbiol Infect 2008; 14: 29-34.

86 Pan A, Battisti A, Zoncada A, et al. Community-acquired methicillin-resistant Staphylococcus aureus ST398 infection, Italy. Emerg Infect Dis 2009; 15: 845-847.

87 Wulf M, Voss A. MRSA in livestock animals-an epidemic waiting to happen? Clin Microbiol Infect 2008; 14: 519-521. 